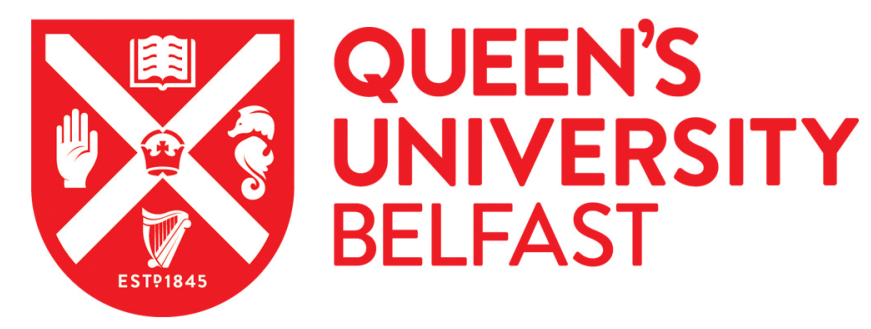

\title{
Electrical characterisation of PVD germanium resistors with rapid melt growth (RMG) process
}

Zainal, N., Mitchell, S. J. N., \& McNeill, D. W. (2018). Electrical characterisation of PVD germanium resistors with rapid melt growth (RMG) process. In AIP Conference Proceedings (1 ed., Vol. 2030). [020109] (AIP Conference Proceedings; Vol. 2030). AIP Publishing. https://doi.org/10.1063/1.5066750

\section{Published in:}

AIP Conference Proceedings

\section{Document Version:}

Peer reviewed version

Queen's University Belfast - Research Portal:

Link to publication record in Queen's University Belfast Research Portal

Publisher rights

(C) 2018 The Authors.

This work is made available online in accordance with the publisher's policies. Please refer to any applicable terms of use of the publisher.

\section{General rights}

Copyright for the publications made accessible via the Queen's University Belfast Research Portal is retained by the author(s) and / or other copyright owners and it is a condition of accessing these publications that users recognise and abide by the legal requirements associated with these rights.

Take down policy

The Research Portal is Queen's institutional repository that provides access to Queen's research output. Every effort has been made to ensure that content in the Research Portal does not infringe any person's rights, or applicable UK laws. If you discover content in the Research Portal that you believe breaches copyright or violates any law, please contact openaccess@qub.ac.uk. 


\title{
Electrical Characterisation of PVD Germanium resistors with Rapid Melt Growth (RMG) process
}

\author{
N Zainal ${ }^{1, a)}$, S J N Mitchell2,b), D W McNeill²,c) \\ ${ }^{1}$ Faculty of Electrical \& Electronic Engineering (FKEE), Universiti Tun Hussein Onn Malaysia (UTHM), 86400 \\ Parit Raja, Batu Pahat, Johor, Malaysia \\ ${ }^{2}$ School of Electronics, Electrical Engineering and Computer Science, Queens University Belfast, BT9 5AH, \\ Northern Ireland. \\ ${ }^{a)}$ Corresponding author: nurfarina@uthm.edu.my \\ b)n.mitchell@qub.ac.uk \\ c)dw.mcneill@qub.ac.uk
}

\begin{abstract}
This paper presents the electrical characterisation of germanium stripe resistors produced by Physical Vapour Deposition using a Rapid Melt Growth process with either single or multiple micro-crucible materials. Electrical measurement of single germanium stripe resistors were obtained using a Greek cross test structure whereas four-terminal aluminium rail test structures were used for germanium stripe arrays. The electrical characterisation was conducted under dark conditions. Results showed only a slight reduction in germanium sheet resistance compared to that of as-deposited material even after a high temperature $\left(980^{\circ} \mathrm{C}\right)$ crystal growth process. It is believed that the measurements were compromised by contact and leakage current issues. As a result, the electrical characteristics of crystallised germanium could not be investigated properly and the relationship to Raman measurement was not established.
\end{abstract}

\section{INTRODUCTION}

Enhancement of energy conversion efficiency either in space or terrestrial applications could be obtained by having germanium as a substrate material in multi-junction solar cells [1]. This is due to the wide photoabsoption spectrum, where it is claimed that the indirect band gap of germanium could perform as a tunnel junction in the splitting spectrum (multi-junction) device. It has been reported that the performance of multi-junction devices with germanium substrate is more efficient compared other substrate materials such as GaInAs [2]. By using germanium as substrate the energy conversion efficiency of multi-junction solar cells can be improved by up 3 to $4 \%$ either with III-V or II-VI cells. However, the use of bulk germanium as substrate material in production might not be cost effective. This is because bulk germanium is an expensive and scarce material thus makes it less attractive compared to silicon. A method to overcome the high cost of bulk germanium is by using a small amount of the material. For example instead of using a bulk germanium wafer this can be reduced to a thinner layer, however additional processing will be involved. In recent investigations [3, 4] modification of the generic Rapid Melt Growth (RMG) structure has demonstrated that thick and thin films of good quality crystalline germanium can be produced at high annealing temperature. In the case of energy conversion devices, a thicker germanium film is necessary for efficient energy absorption in the material $[5,6]$. In this study, germanium resistors have been fabricated using Physical Vapour Deposition (PVD) and RMG with different crucible materials. The aim was to investigate the electrical characteristics of the resultant structures in relation to the material crystallinity for development of energy conversion devices. 


\section{METHODOLOGY}

The electrical characteristics of PVD germanium films was evaluated by adopting a Greek cross test structure with aluminium pads for single germanium stripe devices. A four-terminal aluminium rail test structure was used for germanium stripe arrays. Principally, the four-point probe testing method is used to measure sheet resistance of the film, where current is forced between two contacts and voltage drop across the other two contacts is measured. This is also referred as Kelvin measurement after Lord Kelvin [7]. The advantage of using a Greek cross is that the sheet resistance is extracted at the centre of the cross and an accuracy of better than $0.1 \%$ can be achieved [7, 8, 9]. By fabricating many small Greek cross structures on the wafer the uniformity of film resistance can be determined [7]. These factors have made it favourable to be implemented in this study. Moreover, by having aluminium pads the probing measurement is easily repeatable. The design criteria of the Greek cross test structures requires the arm length, $L$ to be greater than arm width, $W(L>2 W)[10,11]$. Secondly, the arms and probe pads should be integrated together to minimise temperature variations during the electrical measurement [11].

\section{Experiment Details}

In this study, the RMG technique was used to fabricate the PVD germanium resistor with different crucible layers. The first method used a single crucible material namely silicon nitride $\left(\mathrm{Si}_{3} \mathrm{~N}_{4}\right)$ and the second used a combination of silicon dioxide $\left(\mathrm{SiO}_{2}\right)$ and hafnium dioxide $\left(\mathrm{HfO}_{2}\right)$. In the case of $\mathrm{Si}_{3} \mathrm{~N}_{4}$ as crucible material, the process begun with deposition of 40 to $50 \mathrm{~nm}$ thick $\mathrm{Si}_{3} \mathrm{~N}_{4}$ on a silicon wafer after the standard cleaning procedure. The nitride was then patterned and etched to make a seed window by reactive ion etching (RIE) prior to germanium deposition. For the multiple insulator layer structure $\mathrm{SiO}_{2}$ was grown and patterned to make a seed window. A 20 $\mathrm{nm}$ thick $\mathrm{HfO}_{2}$ was then deposited using atomic layer deposition (ALD). The samples were then re-patterned and the $\mathrm{HfO}_{2}$ etched with the same seed window pattern. The step height was measured on each sample using an Alpha step to ensure that the seed region was formed before germanium deposition. The germanium film was deposited on all structures using sputtering.

The germanium film was patterned into stripes and Greek-cross shapes by etching using RIE. A $1 \mu \mathrm{m}$ thick layer of plasma-enhanced chemical vapour deposition (PECVD) oxide was deposited followed by $1 \mu$ m of polycrystalline silicon (poly-Si) as capping layer. Heat treatment was applied on the test samples through rapid thermal annealing (RTA) to crystallise the germanium film. Figure 1 shows the cross-sectional images of the micro-crucible structures. To form the electrical characterisation test structures the polysilicon cap was removed by etching after the crystal growth process. The PECVD oxide cap was dehydrated at $150{ }^{\circ} \mathrm{C}$ for 1 hour before patterning the contact window via RIE. An aluminium film was then deposited using evaporation and patterned into the required shapes.

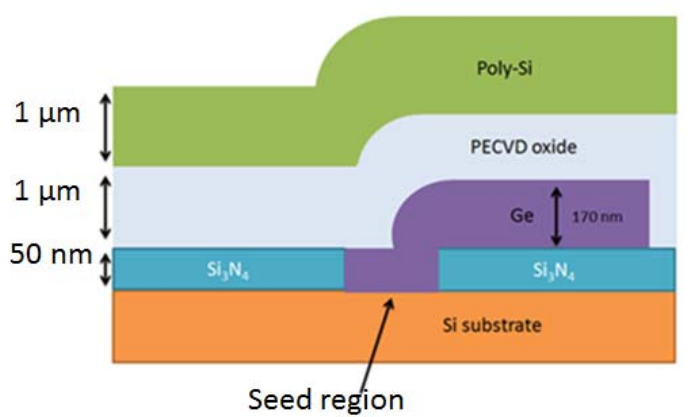

(a)

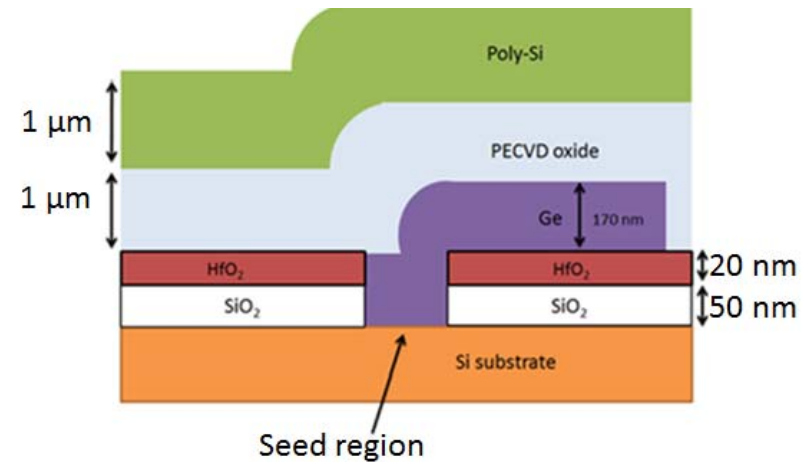

(b)

FIGURE 1. (a) Schematic cross-section of $\mathrm{Ge}$ on $\mathrm{Si}_{3} \mathrm{~N}_{4}$ with capping layer and (b) $\mathrm{Ge}$ on $\mathrm{HfO}_{2}$ with capping layer (not to scale).

In this investigation, a Greek cross structure was designed to examine sheet resistance of single germanium stripes produced by the crystal growth process. The stripe was extended and divided into four arms to form a cross. The stripe was designed with widths of $5 \mu \mathrm{m}$ and $10 \mu \mathrm{m}$ in order to see any differences in electrical characteristics. Figure 2 (a) depicts the photomask design with a $10 \mu \mathrm{m}$ wide extended stripe and Greek cross connecting to $100 \mu \mathrm{m}$ $\times 100 \mu \mathrm{m}$ aluminium pads. To measure arrays of germanium stripes, aluminium rails across the stripes were also 
designed with four $10 \mu \mathrm{m}$ wide aluminium rails across the stripes connected to $100 \mu \mathrm{m} \times 100 \mu \mathrm{m}$ aluminium pads as depicted in figure $2(\mathrm{~b})$.

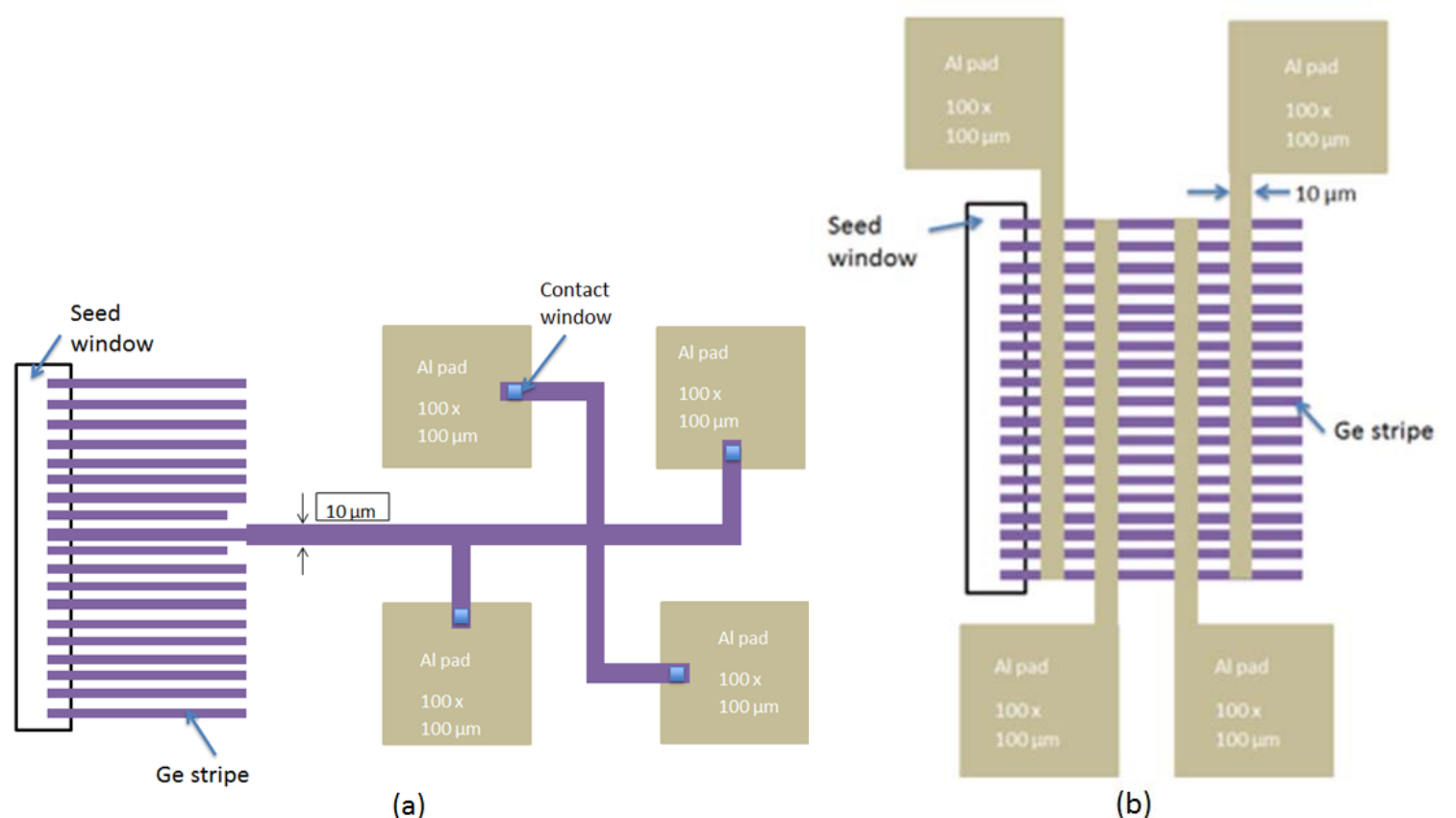

FIGURE 2. (a) Photomask design of germanium stripe with Greek cross test structure and (b) aluminium rails going through arrays of germanium stripes and connecting to aluminium pads.

\section{RESULTS AND DISCUSSIONS}

Prior to I-V measurement, the samples were inspected through optical microscopy and Scanning Electron Microscopy. It can be observed that no delamination can be detected on the samples and the arms are in good position with the aluminium pads and contact windows. Figure 3 shows images of Greek cross test structures before and after metal deposition.

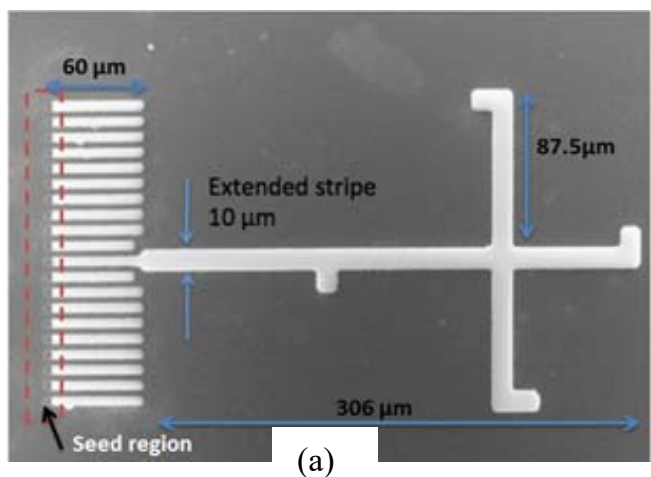

(a)

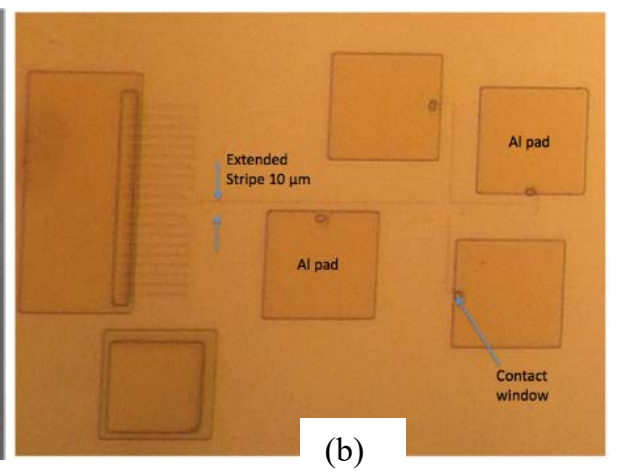

(b)

FIGURE 3. Image of Greek-cross test structure with $10 \mu \mathrm{m}$ wide extended germanium stripe (a) before and (b) after metal contact deposition.

All samples were measured under dark condition (no illumination). Measurements were first conducted on $170 \mathrm{~nm}$ thick blanket germanium using a standard four-point probe and Agilent parameter analyser. This sample was 
used as a control for comparison to the germanium stripe resistors. Under the dark condition, the average sheet resistance measured from this blanket film was $1.6 \times 10^{6} \Omega / \square$. It is reported [5] that the resistivity of intrinsic bulk germanium at $300 \mathrm{~K}$ is $47 \Omega . \mathrm{cm}$. Thus, by referring to the sheet resistance, $R_{\text {sh }}$ equation (1) [5, 7], the calculated sheet resistance of $170 \mathrm{~nm}$ thick intrinsic bulk germanium is $2.8 \times 10^{6} \Omega / \square$, which is slightly higher than the measured as-deposited germanium test sample. The difference is believed to be due to incorporation of a trace level of dopant in the deposited films.

$$
R_{s h}=\frac{\rho}{t}=\frac{\pi}{\ln 2} \frac{V}{I}=4.532 \frac{V}{I} \Omega / \mathrm{sq}
$$

For germanium stripe resistors, various RTA temperatures from $942{ }^{\circ} \mathrm{C}$ to $980{ }^{\circ} \mathrm{C}$ were applied to samples to see how electrical resistivity related to crystalline quality. It would be expected that much lower sheet resistance would be obtained after high annealing temperature compared to as-deposited samples. This assumption is based on the results attained from Raman measurements reported previously [3, 12], where better crystallinity of germanium was produced at higher annealing temperatures. Figure 4 (a) illustrates Greek cross structure with four terminals, where a fixed current was forced between pads 1 and 2, and resulting potential different was measured between pads 3 and 4 . Currents were then reversed and the voltage drop was re-measured. The voltage and current pads were then interchanged so that current was forced into pads 1 and 4 and the voltage drop was measured from pads 2 and 3 . Finally, the current was reversed and the measurement repeated. The values of all resistance measurements were then averaged. The cross section of part of the structure is shown in figure 4 (b).

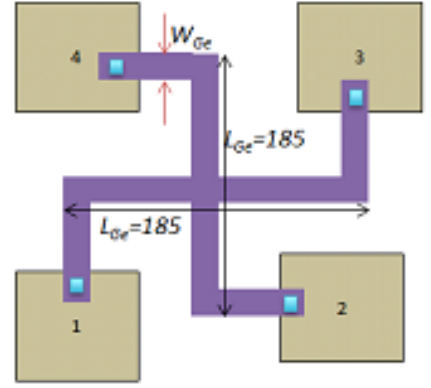

(a) Top view

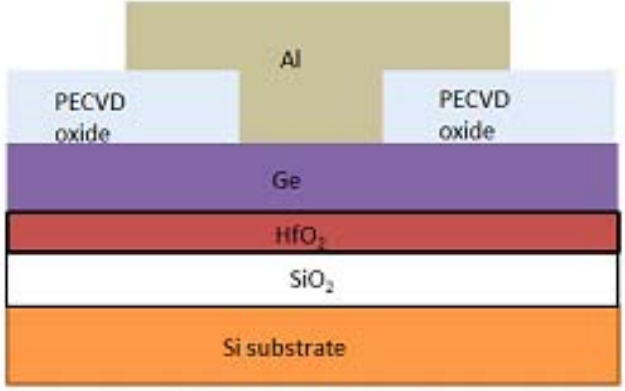

(b) Cross sectional view

FIGURE 4. Illustration of Greek cross test structure for sheet resistance measurement with inset (a) top view and (b) crosssectional of germanium on $\mathrm{HfO}_{2}$ (not to scale).

In the first inspection, a $1 \mu \mathrm{A}$ current was forced into samples that were annealed at $980{ }^{\circ} \mathrm{C}$, the sheet resistance obtained from the Greek cross test structure was $0.5 \times 10^{9} \Omega / \square$ and for germanium stripe arrays was $0.2 \times 10^{9} \Omega / \square$. There are several factors that could cause such high sheet resistance values. Firstly it is suspected that there may be poor metal contact to Ge. In an effort to improve the contact, the samples were given a post metal anneal (PMA) at $350{ }^{\circ} \mathrm{C}$ for 30 minutes. According to DiLello et al., [13] the PMA can improve the electrical properties of germanium devices. However, there was no improvement in resistance values after the PMA. Additional investigation was carried out by removing the aluminium and oxide layers, re-depositing the aluminium directly on the germanium and re-patterned to form metal contact. This was done to minimise any problems that may have occurred with the contact window. However, again the results on both single stripes and arrays of germanium stripes still showed high sheet resistance values.

According to Sze et al., [5] when metal and semiconductor material are in contact, a barrier can be present, which limits the current through the device, namely a Schottky barrier. Ideally, for good electrical characteristic this barrier should be low enough that current can easily pass. One way to lower the barrier height is by doping the intrinsic material. Gajula et al., [14] reported that the optimum Schottky barrier height that can be obtained is $0.63 \mathrm{eV}$ via n-doped nickel germanide with annealing temperature at $300^{\circ} \mathrm{C}$. Averine et al., [15] have stated that the presence of native oxide at the metal-semiconductor interface could also increase the height barrier. In consideration of these published works, it is believed that the interface between metal contact and the intrinsic 
germanium resistor fabricated in this investigation have a Schottky instead of ohmic contact. This has affected the electrical performance, which results in higher effective resistance even though excellent germanium crystalline quality may have been obtained. The presence of native oxide, given that germanium that can easily be oxidised, may also have increased the barrier height. In attempt to improve the contact, another investigation was carried out by applying higher currents of up to $10 \mathrm{~mA}$ to the test samples. The results showed that when forcing higher currents, a reduction in sheet resistances was obtained. Figure 5 shows the I-V measurement results of several Greek cross test samples. The resistance value of each sample was calculated by measuring the slope and these values are then averaged. The same calculation was applied and repeated to other electrical measurement setups as explained previously. Thus the overall average resistances of Greek cross test structures were calculated.

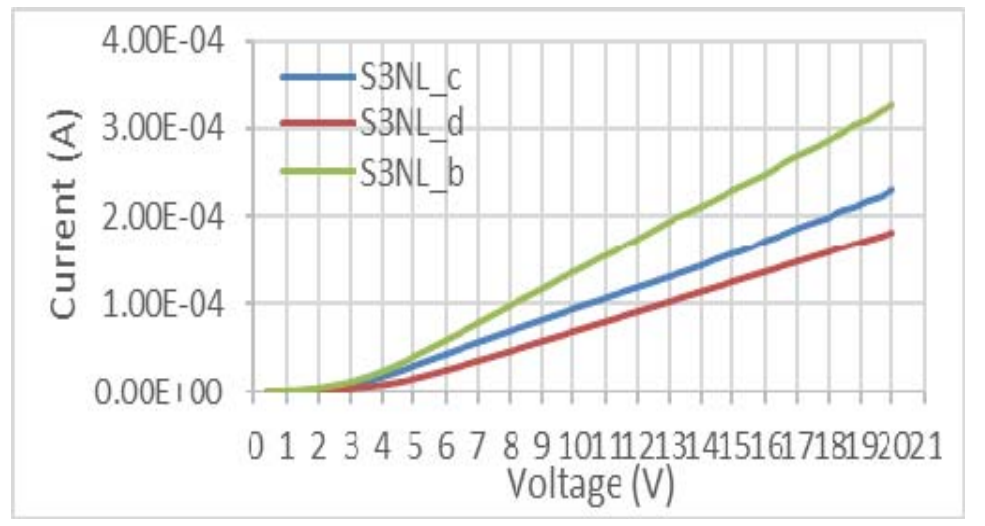

FIGURE 5. I - V measurement results of different samples Greek cross test structure.

Equation (2) [5] shows the calculation of Greek cross sheet resistance for different I-V measurement setups, where $\Delta V$ is the average voltage change and $\Delta I$ the average current change. For the test structures annealed at $980^{\circ} \mathrm{C}$, the minimum, maximum and overall average resistance values were $26.3 \times 10^{3} \Omega, 85 \times 10^{3} \Omega$, and $48 \times 10^{3} \Omega$, respectively. This corresponds to a germanium minimum sheet resistance of $0.22 \times 10^{6} \Omega / \square$. For the arrays of germanium stripes, the electrical measurement was carried out using Kelvin measurement with four aluminium pads and rails. The current was applied in one direction and then reversed, resistance values were calculated from the slope of the I-V characteristics. The average sheet resistances were then calculated using equation (3) [7]. In this investigation there were 20 parallel germanium stripes in the arrays. The overall average value of resistance is $R$, the width of germanium stripe is $w$ and the length of germanium stripe is $L$. For test samples annealed at $980{ }^{\circ} \mathrm{C}$ the minimum, maximum and overall average resistance values were $1.6 \times 10^{3}, 3.38 \times 10^{3}$ and $2.02 \times 10^{3} \Omega$, respectively. Results from the electrical measurements are summarized in table 1 .

$$
\begin{aligned}
& R_{s h}=4.532 \frac{\Delta V}{\Delta I} \\
& R_{s h}=R \frac{w}{L} N
\end{aligned}
$$

TABLE 1. Summary of average sheet resistance values of germanium samples.

\begin{tabular}{cc}
\hline $\begin{array}{c}\mathbf{1 7 0} \text { nm thick Ge } \\
\text { condition }\end{array}$ & $\begin{array}{c}\text { Dark (No illumination) } \\
\text { Sheet resistance }(\boldsymbol{\Omega} / \square)\end{array}$ \\
\hline as - deposited Ge film & $1.6 \times 10^{6}$ \\
$\begin{array}{c}\text { Single Ge stripe }(\text { Greek cross) } \\
\text { annealed at } 980^{\circ} \mathrm{C}\end{array}$ & $0.2 \times 10^{6}$ \\
Ge stripe arrays anneal at $980^{\circ} \mathrm{C}$ & $2.02 \times 10^{3}$ \\
\hline
\end{tabular}


Table 1 shows the electrical measurement results of germanium samples under dark condition. The germanium stripe resistors measured using the Greek cross test structure have a sheet resistance of $0.2 \times 10^{6} \Omega / \square$ even after a high temperature RMG process. It was expected that lower sheet resistance would have been achieved due better crystalline quality of the germanium. However, the sheet resistance is only slightly lower than that of amorphous as-deposited material $\left(1.6 \times 10^{6} \Omega / \square\right)$. In the case of germanium stripe arrays a much lower sheet resistance of $2.02 \times 10^{3} \Omega / \square$ was obtained. These reasons for this lower value were unclear, so additional investigations were conducted. A test for leakage to substrate was carried out by breaking the germanium stripe near to the seed window on both Greek cross and germanium stripe array test structures to isolate the devices from the substrate. Electrical tests revealed a leakage current flow to substrate. Since the contact windows are larger than the germanium stripe, a leakage path to the substrate may have been formed during the etching process even though the $\mathrm{HfO}_{2}$ should have resisted this etching. Electrical measurements have been compromised due to this leakage to the substrate. As a result, the electrical measurement on crystallised germanium could not be investigated properly and the relation to Raman measurement could not be established.

\section{CONCLUSIONS}

In conclusion, electrical characterisations of PVD germanium films have been investigated under dark condition. The use of a rapid melt growth technique was expected to produce germanium films with good crystallinity and hence reduced resistivity compared to as-deposited films. However, results obtained using a Greek-cross test structure displayed only a small reduction in sheet resistance after a crystallisation process at $980{ }^{\circ} \mathrm{C}$. It is believed that current flow may have been limited by the non-ohmic nature of metal contacts to the undoped germanium. The inclusion of a doped region at the contact windows is recommended for any future fabrication.

In the case of germanium stripe arrays, it is believed that oversize contacts in the test structures enabled current leakage paths to form to the substrate during the etching process. Measurements on these structures were thus compromised. It is recommended that changes are made to the process sequence and contact window design to avoid this issue.

\section{ACKNOWLEDGMENTS}

This work was under the financial support short term grant (Vot U352) of Universiti Tun Hussein Onn Malaysia and in collaboration with Queen's University Belfast, Northern Ireland, United Kingdom.

\section{REFERENCES}

1. R. R. King, C. M. Fetrer, P. C. Colter, K. M. Edmondson, H. E. James, H. L. Cotal, H. Yoon, A. P. Stavrides, G. Kinsey, D. D. Krut, and N. H. Karam, "High-Efficiency Space and Terrestrial Multijunction Solar Cells Through Bandgap Control in Cell Structures" (IEEE Photovoltaic Specialist Conference, 2002) pp. 776-781.

2. M. Bosi and G. Attolini, Prog. Crystal. Growth Characterisation Material, 146-174 (2010).

3. N. Zainal, S. Mitchell, D. McNeill, M. F. Bain, B. M. Armstrong, P. Baine, D. Adley, and T. S. Perova, ECS Transaction 45(4), 169-180 (2012).

4. N. Zainal, S. J. N. Mitchell and D. W. McNeill, "Hafnium dioxide $\left(\mathrm{HfO}_{2}\right)$ as micro-crucible liner on GeOI for Rapid Melt Growth (RMG) structure" Journal of Telecommunication, Electronic and Computer Engineering, 9, 137-140 (2017).

5. S. M. Sze and Kwok K. Ng, "Physics of Semiconductor Devices"( 3rd edit., A John Wiley and Sons Inc. Publication,. New Jersey and Canada, 2007).

6. S. M. Sze and M. K. Lee, "Semiconductor Devices Physics and Technology" (3rd edit. A John Wiley and Sons, Inc., Publication, Singapore, 2013).

7. D. K. Schroder, "Semiconductor Material and Device Characterization" ( $3^{\text {rd }}$. Edit., A John Wiley and Sons, Inc., Publication, Tempe, Arizona, 2006)

8. S. Enderling, C. L. Brown, S. Smith, M. H. Dicks, J. T. M. Stevenson, M. Mitkova, M. N. Kozicki, A. J. Walton, and N. Si, IEEE Transaction Semiconductor Manufacturing 19, 2-9, (2006). 
9. A. W. Groenland, R. A. M. Wolters, A. Y. Kovalgin and J. Schmitz, "Four point probe structure with buried electrodes for the electrical characterization of ultrathin conducting film" (IEEE International Conference Microelectronic Test Structure, 2009), pp. 191-195.

10. M. G. Buehler, S. D. Grant and W. R. Thurber, Journal Electrochemical. Society Solid-State Science Technolology 125, 650-654, (1978).

11. S. Enderling, M. H. Dicks, S.Smith, J. T. M. Stevenson and A. J. Walton, IEEE Transaction Semiconductor Manufacturing 17, 84-90 (2004).

12. Y. Liu, M. D. Deal, and J. D. Plummer, Applied Physics Letters 84, 2563 (2004).

13. N. A. DiLello, D. K. Johnstone, and J. L. Hoyt, Journal of Applied Physics, 112, 054506 (2012).

14. D. R. Gajula, D. W. McNeill, B. E. Coss, H. Dong, S. Jandhyala, J. Kim, R. M. Wallace, and B. M. Armstrong, Applied Physics Letters 100, 192101 (2012).

15. S. Averine, Y. C. Chan, and Y. L. Lam, Applied Physics Letters 112, 054506 (2000). 